\title{
Clinical Significance of Cardio-Ankle Vascular Index as a Cardiovascular Risk Factor in Elderly Patients With Type 2 Diabetes Mellitus
}

\author{
Takashi Hitsumoto
}

\begin{abstract}
Background: The cardio-ankle vascular index (CAVI) is a novel physiological marker of atherosclerosis that reflects systemic arterial stiffness. The aim of this study was to clarify the clinical significance of CAVI as a risk factor for cardiovascular diseases (CVDs) in elderly patients with type 2 diabetes mellitus.
\end{abstract}

Methods: This cross-sectional study enrolled 216 elderly ( $\geq 65$ years) outpatients with type 2 diabetes mellitus who were undergoing antidiabetic treatment (96 males and 120 females; mean age, $75 \pm 7$ years (mean \pm standard deviation)). Associations between CAVI and various clinical parameters were examined.

Results: CAVI was significantly higher in patients with a history of CVD than in those without a history of CVD (10.4 \pm 1.4 vs. $9.5 \pm 1.0$, respectively, $\mathrm{P}<0.001)$. There were significantly positive correlations between CAVI and various clinical parameters, such as skin autofluorescence $(\mathrm{r}=0.47, \mathrm{P}<0.001)$, high-sensitivity cardiac troponin $\mathrm{T}$ levels $(\mathrm{r}=0.39, \mathrm{P}<0.001)$, and reactive oxygen metabolite levels $(\mathrm{r}=0.28, \mathrm{P}<0.001)$. Furthermore, multiple regression analyses revealed that these clinical parameters ((skin autofluorescence $(\beta=0.30, \mathrm{P}<0.001)$, high-sensitivity cardiac troponin T levels $(\beta=0.18, \mathrm{P}<0.001)$, reactive oxygen metabolite levels $(\beta=0.15, \mathrm{P}<0.01)$, and a history of CVD $(\beta=0.19, \mathrm{P}<$ $0.001)$ ) were independent variables when CAVI was used as a subordinate factor.

Conclusion: Findings of this study indicate that CAVI may be an important CVD risk factor in elderly patients with type 2 diabetes mellitus. Further investigations in a large number of prospective studies, including intervention therapies, are required to validate our results.

Keywords: Cardio-ankle vascular index; Cardiovascular risk factors; Skin autofluorescence; High-sensitivity cardiac troponin T; Oxidative stress; Elderly; Type 2 diabetes mellitus

Manuscript submitted January 19, 2018, accepted January 29, 2018

Hitsumoto Medical Clinic, 2-7-7, Takezakicyou, Shimonoseki City, Yamaguchi 750-0025, Japan. Email: thitsu@jcom.home.ne.jp

doi: https://doi.org/10.14740/jocmr3364w

\section{Introduction}

Type 2 diabetes mellitus is one of the most important risk factors for cardiovascular diseases (CVDs). The population of elderly patients with type 2 diabetes mellitus has been increasing worldwide due to extended life expectancy [1-3]. Therefore, to prevent CVD, it is important to consider a diagnostic or therapeutic strategy for elderly patients with type 2 diabetes mellitus as well as for young-to-middle-aged patients with type 2 diabetes mellitus.

Arterial dysfunction is an important factor for CVD incidence. Among physiological markers of arterial function, the cardio-ankle vascular index (CAVI) is a novel marker of atherosclerosis, which reflects arterial stiffness in the aorta, femoral, and tibial arteries [4]. This stiffness parameter has been reported to be independent of blood pressure levels during measurements. Furthermore, some clinical studies have indicated that CAVI is significantly associated with macro- and microvascular complications in patients with type 2 diabetes mellitus $[5,6]$.

To the best of our knowledge, there are no reports regarding the clinical significance of CAVI as a CVD risk factor in elderly patients with type 2 diabetes mellitus. Therefore, this cross-sectional study attempts to clarify the clinical significance of CAVI as a risk factor for CVD in elderly patients with type 2 diabetes mellitus.

\section{Materials and Methods}

\section{Patients}

Patients in this study were enrolled between August 2015 and July 2017 . The study population comprised 216 elderly outpatients ( $\geq 65$ years) with type 2 diabetes mellitus, who were undergoing antidiabetic treatment at the Hitsumoto Medical Clinic. The patients included 96 (44.4\%) males and 120 (55.6\%) females, with a mean age of $75 \pm 7$ years (mean \pm standard deviation). All participants provided informed consents, and the local Ethics Committee approved the study protocol.

\section{CAVI measurement}

CAVI was measured using a VaSera CAVI instrument (Fuku- 
da Denshi, Tokyo, Japan) following the previously described methods [4]. Briefly, the brachial and ankle pulse waves were determined using inflatable cuffs with the pressure maintained between 30 and $50 \mathrm{~mm} \mathrm{Hg}$ to ensure that the cuff pressure had a minimal effect on the systemic hemodynamics. Systemic blood and pulse pressures were simultaneously determined, with the participant in a supine position. CAVI was measured after the participants had rested for $10 \mathrm{~min}$ in a quiet room. The average coefficient of variation in CAVI has been shown to be less than $5 \%$, which is small enough for clinical use and indicates that CAVI measurement has good reproducibility.

\section{Estimation of cardiovascular risk factors}

Various clinical parameters, such as classic CVD risk factors, blood glucose-related parameters, kidney function, brain natriuretic peptide (BNP) levels, high-sensitivity cardiac troponin T (hs-cTnT) levels, and oxidative stress were evaluated. Obesity was identified using body mass index, calculated as the weight $(\mathrm{kg})$ divided by the squared height $\left(\mathrm{m}^{2}\right)$. Current smoking was defined as smoking at least one cigarette per day during the previous 28 days. The right brachial blood pressure was measured twice using a mercury sphygmomanometer, with participants in the sitting position. An average of two readings was used to determine the systolic and diastolic blood pressures. Hypertension was defined as a systolic blood pressure of $\geq 140 \mathrm{~mm} \mathrm{Hg}$, a diastolic blood pressure of $\geq 90 \mathrm{~mm} \mathrm{Hg}$, or any blood pressure value in those using antihypertensive medication. Blood samples were collected from the antecubital vein in the morning after $12 \mathrm{~h}$ of fasting. Total cholesterol and triglyceride levels were measured using standard enzymatic methods. Serum high-density lipoprotein cholesterol levels were measured by selective inhibition. Serum low-density lipoprotein cholesterol levels were calculated using the Friedewald equation [7]. Dyslipidemia was defined as low-density lipoprotein cholesterol levels of $\geq 140 \mathrm{mg} / \mathrm{dL}$, high-density lipoprotein cholesterol levels of $\leq 40 \mathrm{mg} / \mathrm{dL}$, triglyceride levels of $\geq 150 \mathrm{mg} / \mathrm{dL}$, or on the basis of an ongoing treatment for dyslipidemia. Glucose and insulin levels were measured using the glucose oxidase method and an enzyme immunoassay, respectively. To measure insulin resistance, HOMA-IR was calculated using the following equation [8]: HOMA-IR = fasting glucose concentration $(\mathrm{mg} / \mathrm{dL}) \times$ fasting insulin concentration $(\mu \mathrm{g} / \mathrm{mL}) / 405$. The hemoglobin A1c levels were expressed using the National Glycohemoglobin Standardization Program. Skin autofluorescence (AF), which reflects the accumulation of advanced glycation end products (AGEs) on the skin, was measured on the volar side of the forearm using a commercial instrument (AGE Reader ${ }^{\mathrm{TM}}$; DiagnOptics, Groningen, The Netherlands) as previously described [9]. Estimated glomerular filtration rate (eGFR) was calculated using the adjusted Modification of Diet in Renal Disease Study equation, which was proposed by the working group of the Japanese Chronic Kidney Disease Initiative [10]. BNP levels were measured using a commercial kit (SHIONOSPOT Reader; Shionogi \& Co., Osaka, Japan), and hs-cTnT levels were also measured using a commercial kit (Roche Diagnostics, Switzerland) [11]. As a maker of oxidative stress in vivo [12], the reactive oxygen
Table 1. Patient Characteristics

\begin{tabular}{|c|c|}
\hline n (male/female) & $216(96 / 120)$ \\
\hline Age (years) & $75 \pm 7$ \\
\hline CVD, n $(\%)$ & $73(34)$ \\
\hline Body mass index & $23.5 \pm 4.3$ \\
\hline Current smoker, n (\%) & $46(21)$ \\
\hline Hypertension, n (\%) & $156(72)$ \\
\hline Systolic blood pressure (mm Hg) & $141 \pm 21$ \\
\hline Diastolic blood pressure (mm Hg) & $86 \pm 13$ \\
\hline Dyslipidemia, n (\%) & $130(60)$ \\
\hline Total cholesterol (mg/dL) & $219 \pm 42$ \\
\hline LDL-cholesterol (mg/dL) & $138 \pm 38$ \\
\hline Triglyceride (mg/dL) & $145 \pm 57$ \\
\hline HDL-cholesterol (mg/dL) & $49 \pm 18$ \\
\hline Fasting blood glucose (mg/dL) & $134 \pm 26$ \\
\hline HOMA-IR & $2.5 \pm 1.3$ \\
\hline Hemoglobin A1c (\%) & $7.2 \pm 1.0$ \\
\hline Skin autofluorescence (AU) & $2.7 \pm 0.6$ \\
\hline eGFR (mL/min/1.73 m²) & $62.0 \pm 19.5$ \\
\hline $\log -\mathrm{BNP}(\mathrm{pg} / \mathrm{mL})$ & $1.7 \pm 0.3$ \\
\hline Log-hs-cTnT (ng/mL) & $-2.1 \pm 0.2$ \\
\hline d-ROMs test (U. CARR) & $365 \pm 113$ \\
\hline CAVI & $9.8 \pm 1.2$ \\
\hline \multicolumn{2}{|l|}{ Medication } \\
\hline Sulfonylurea, n (\%) & $151(70)$ \\
\hline Metformin, n (\%) & $43(20)$ \\
\hline DPP-4 inhibitor, n (\%) & $125(58)$ \\
\hline Insulin, n (\%) & $17(8)$ \\
\hline RAS inhibitor, n (\%) & $118(55)$ \\
\hline Statin, n (\%) & $95(44)$ \\
\hline
\end{tabular}

Continuous values are mean \pm SD. CVD: cardiovascular disease; LDL: low-density lipoprotein; HDL: high-density lipoprotein; HOMA-IR: homeostasis assessment insulin resistance; eGFR: estimated glomerular filtration rate; BNP: brain natriuretic peptide; hs- cTnT: high-sensitivity cardiac troponin T; d-ROMs: derivatives of reactive oxygen metabolites; CAVI: cardio-ankle vascular index; DPP: dipeptidyl peptidase; RAS: renin-angiotensin system.

metabolites (d-ROMs) test was performed using a commercial kit (Diacron, Grosseto, Italy).

\section{Statistical analysis}

A commercially available statistical software program (Stat View-J 5.0; HULINKS, Tokyo, Japan) was used for all statistical analyses. Data in the study are expressed as mean \pm standard deviation. Between-group comparisons were performed using Student's $t$-test. Simple regression analysis was performed using the Spearman rank correlation, and a multi- 


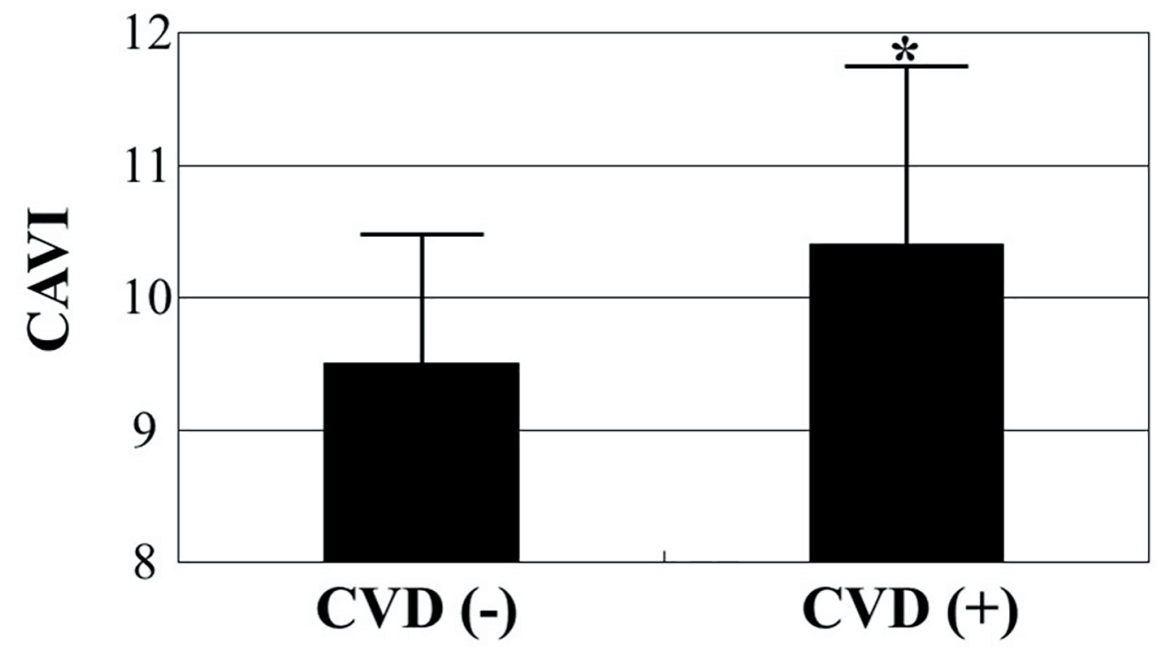

Figure 1. Comparisons of CAVI values between patients with and without CVD. CAVI was significantly higher in patients with CVD than in those without CVD $(10.4 \pm 1.4$ vs. $9.5 \pm 1.0$, respectively, $\mathrm{P}<0.001)$ even though mean age was similar between the two groups (76 \pm 7 years vs. $75 \pm 7$ years, respectively). ${ }^{*} P<0.001$ vs. CVD (-). CAVI: cardio-ankle vascular index; CVD: cardiovascular disease.

variate analysis was performed using multiple regression or multiple logistic regression analyses. A P-value of $<0.05$ was considered statistically significant.

\section{Results}

Table 1 summarizes patient characteristics. In total, 73 (34\%) patients had a history of CVD, such as coronary artery disease, cerebrovascular disease, or heart failure, upon admission. Mean CAVI level was $9.8 \pm 1.2$, ranging from 7.5 to 14.5 . Figure 1 presents comparisons of CAVI levels between patients with CVD and those without CVD. CAVI was significantly higher in patients with CVD than in those without CVD $(10.4 \pm 1.4 \mathrm{vs}$. $9.5 \pm 1.0$, respectively, $\mathrm{P}<0.001)$ even though mean age was similar between the two groups. Table 2 presents correlations between CAVI and various clinical parameters. Age, systolic blood pressure, HOMA-IR, skin AF, eGFR, BNP levels, hs$\mathrm{cTnT}$, and the d-ROMs test significantly correlated with CAVI.

Table 3 summarizes results of a multiple regression analysis with CAVI as a subordinate factor. Explanatory factors were selected by examining multicollinearity among the variables or by conducting a stepwise method. Skin AF, CVD, hscTnT, d-ROMs test, and age were identified as independent variables when CAVI was used as a subordinate factor. When coronary artery disease was used as an explanatory factor instead of CVD, coronary artery disease was also selected as an independent variable for CAVI as a subordinate factor $(\beta=$ $0.14, \mathrm{P}<0.01$ ). To illustrate the simple threshold of CAVI for detecting CVD or high hs-cTnT, participants were divided into three groups according to their CAVI values, and a multiple logistic regression analysis was performed (Fig. 2). Patients with a high CAVI $(\geq 10)$ or a moderate CAVI $(9.1-9.9)$ showed a significantly higher risk (OR, 7.3 (95\% CI: 2.2 - 19.6), $\mathrm{P}<$ 0.001; OR, 2.2 (95\% CI: $1.1-4.2), \mathrm{P}<0.05$, respectively) of developing a CVD than those with a low CAVI $(\leq 9)$. In con- trast, patients with a high or moderate CAVI had a significantly higher risk (OR, 10.0 (95\% CI: 2.3 - 29.4), $\mathrm{P}<0.001$; OR, 3.6 ( $95 \%$ CI: 1.3 - 9.6), $\mathrm{P}<0.05$, respectively) of having a high hscTnT level $(\geq 0.014 \mathrm{ng} / \mathrm{mL})$ than those with a low CAVI $(\leq 9)$.

\section{Discussion}

Clinical studies have shown an association between CAVI and CVD including coronary artery disease [5, 13-15]. The results of this cross-sectional study also indicate that CAVI levels are higher in patients with CVD than in patients without CVD even when their mean age is similar. Furthermore, a history of CVD or coronary artery disease was identified as an independent variable for CAVI (as a subordinate factor), suggesting that CAVI is a considerable risk factor for CVD in elderly patients with type 2 diabetes mellitus.

Among glucose-related factors, only skin AF was independently associated with CAVI in our study. To the best of our knowledge, this is the first report of an independent association between skin AF and CAVI in patients with type 2 diabetes mellitus. Basic studies have reported that AGEs or their receptors can induce inflammation, oxidative stress, and calcification in vascular cells, such as endothelial or smooth muscle cells [16-18]. Moreover, clinical studies have also indicated a significant association between skin AF and physiological markers of arterial function [19, 20]. In contrast, AGEs are considered to be markers expressing "hyperglycemic memory" [21], and a study regarding the association between skin $\mathrm{AF}$ and $\mathrm{HbA} 1 \mathrm{c}$ levels has reported that skin AF level was significantly associated with means of the last five and $10 \mathrm{HbAlc}$ values [22]. Thus, taken together, all these results suggest that long-term glucose control is necessary to maintain arterial function in patients with type 2 diabetes mellitus.

Basic science and clinical studies support a role of oxidative stress in the pathogenesis of CVD in patients with un- 
Table 2. Relationship Between CAVI and Various Clinical Parameters

\begin{tabular}{|c|c|c|}
\hline & $\mathbf{r}$ & P value \\
\hline Sex $($ female $=0$, male $=1)$ & 0.12 & 0.079 \\
\hline Age & 0.19 & $<0.001$ \\
\hline Body mass index & 0.04 & 0.566 \\
\hline Current smoker $($ no $=0$, yes $=1)$ & 0.11 & 0.105 \\
\hline Hypertension $($ no $=0$, yes $=1)$ & 0.13 & 0.059 \\
\hline Systolic blood pressure & 0.30 & $<0.001$ \\
\hline Diastolic blood pressure & 0.11 & 0.112 \\
\hline Dyslipidemia $($ no $=0$, yes $=1)$ & 0.08 & 0.288 \\
\hline Total cholesterol & -0.04 & 0.587 \\
\hline LDL-cholesterol & 0.07 & 0.320 \\
\hline Triglyceride & -0.04 & 0.488 \\
\hline HDL-cholesterol & -0.10 & 0.139 \\
\hline Fasting blood glucose & 0.11 & 0.105 \\
\hline HOMA-IR & 0.14 & $<0.05$ \\
\hline Hemoglobin A1c & 0.12 & 0.079 \\
\hline Skin autofluorescence & 0.47 & $<0.001$ \\
\hline eGFR & -0.17 & $<0.01$ \\
\hline Log-BNP & 0.13 & $<0.05$ \\
\hline Log-hs-cTnT & 0.39 & $<0.001$ \\
\hline d-ROMs test & 0.28 & $<0.001$ \\
\hline Sulfonylurea $($ no $=0$, yes $=1)$ & 0.03 & 0.501 \\
\hline Metformin $($ no $=0$, yes $=1)$ & 0.04 & 0.594 \\
\hline DPP-4 inhibitor $($ no $=0$, yes $=1)$ & -0.06 & 0.320 \\
\hline Insulin $($ no $=0$, yes $=1)$ & 0.02 & 0.739 \\
\hline RAS inhibitor $($ no $=0$, yes $=1)$ & -0.09 & 0.159 \\
\hline Statin $($ no $=0$, yes $=1)$ & -0.10 & 0.142 \\
\hline
\end{tabular}

r expressed correlation coefficient. CAVI: cardio-ankle vascular index; LDL: low-density lipoprotein; HDL: high-density lipoprotein; HOMA-IR: homeostasis assessment insulin resistance; eGFR: estimated glomerular filtration rate; BNP: brain natriuretic peptide; hs-cTnT: high-sensitivity cardiac troponin $\mathrm{T}$; d-ROMs: derivatives of reactive oxygen metabolites; DPP: dipeptidyl peptidase; RAS: renin-angiotensin system.

derlying diabetes mellitus [23, 24]. Furthermore, there is a significant association between oxidative stress in vivo and various physiological markers of arterial function, including CAVI, in diabetic patients [25-29]. Our results also indicate that d-ROMs test (a marker of oxidative stress in vivo) is an independent factor for altered CAVI values in elderly patients with type 2 diabetes mellitus. Previous studies have reported that medications (antidiabetic, antihyperlipidemic, and antihypertension drugs) decrease oxidative stress in vivo [30-32], and improve CAVI values in these patients [25, 26, 33].

Additionally, a decrease in urinary 8-hydroxydeoxyguanosine (a marker of oxidative stress in vivo) showed a significant positive correlation with the decrease in CAVI values after an intervention therapy using statins or angiotensin re-
Table 3. Multiple Regression Analysis for CAVI

\begin{tabular}{lll}
\hline Explanatory factor & $\boldsymbol{\beta}$ & P value \\
\hline Skin autofluorescence & 0.30 & $<0.001$ \\
CVD & 0.19 & $<0.001$ \\
Log-hs-cTnT & 0.18 & $<0.01$ \\
d-ROMs test & 0.15 & $<0.01$ \\
Age & 0.12 & $<0.05$ \\
eGFR & -0.08 & 0.193 \\
$\mathrm{R}^{2}=0.32$ & & \\
\hline
\end{tabular}

CAVI: cardio-ankle vascular index; CVD: cardiovascular disease; hsCTnT: high-sensitivity cardiac troponin T; d-ROMs: derivatives of reactive oxygen metabolites; eGFR: estimated glomerular filtration rate; $\beta$ : standardized regression coefficient; $\mathrm{R}^{2}$ : coefficient of determination.

ceptor blockers in patients with type 2 diabetes mellitus [25, 26]. The results of this study indicate no significant correlation between the type of medication used and CAVI values; however, interventional studies are still required to examine the effectiveness of medications on oxidative stress and CAVI values in elderly patients with type 2 diabetes mellitus; we expect discoveries of new applications of antidiabetic, antihypertensive, and antihyperlipidemic drugs for the prevention of CVD.

Hs-cTnT is a useful biomarker to evaluate myocardial injury in the clinical setting. In addition, epidemiological studies have reported that hs-cTnT is a predictor of CVD events in the general population and in patients with type 2 diabetes mellitus [34]. Clinical studies have indicated a significant association between physiological markers of arterial stiffness and hs-cTnT levels [35,36]. Several studies have indicated that left ventricular dysfunction is significantly associated with myocardial injury [37]; furthermore, increases in aortic artery stiffness cause left ventricular dysfunction [38]. Therefore, we posit that the association between hs-cTnT levels and CAVI identified in this study reflects the presence of myocardial injury via left ventricular dysfunction due to an increased vascular resistance or afterload. Endothelial dysfunction plays a crucial role in the incidence of CVD. Increases in CAVI values may reflect endothelial dysfunction in patients with type 2 diabetes mellitus [39]. Endothelial dysfunction also causes left ventricular dysfunction or myocardial injury $[40,41]$. Thus, the significant association between CAVI and hs-cTnT levels in this study may be partially explained by endothelial dysfunction following subclinical myocardial injuries.

It would be useful to set a target value for predicting CVD in the clinical setting. In this study, to clarify the clinical significance of CAVI measurements in elderly patients with type 2 diabetes mellitus, participants were divided into three groups on the basis of simple cut-off CAVI values and multiple logistic regression analysis was performed for detecting a correlation between CVD incidence and high hs-cTnT level $(\geq 0.014 \mathrm{ng} /$ $\mathrm{mL}$ ), which has been reported to be the cut-off level for predictive CVD incidence rate [42]. Our results indicated that patients with CAVI values of $\geq 10$ or $9.1-9.9$ exhibited a significantly higher risk of CVD and higher hs-cTnT levels than those with CAVI values of $\leq 9$. This result is consistent with a report that a CAVI value of $\geq 9$ is a predictor of cardiovascular events in 

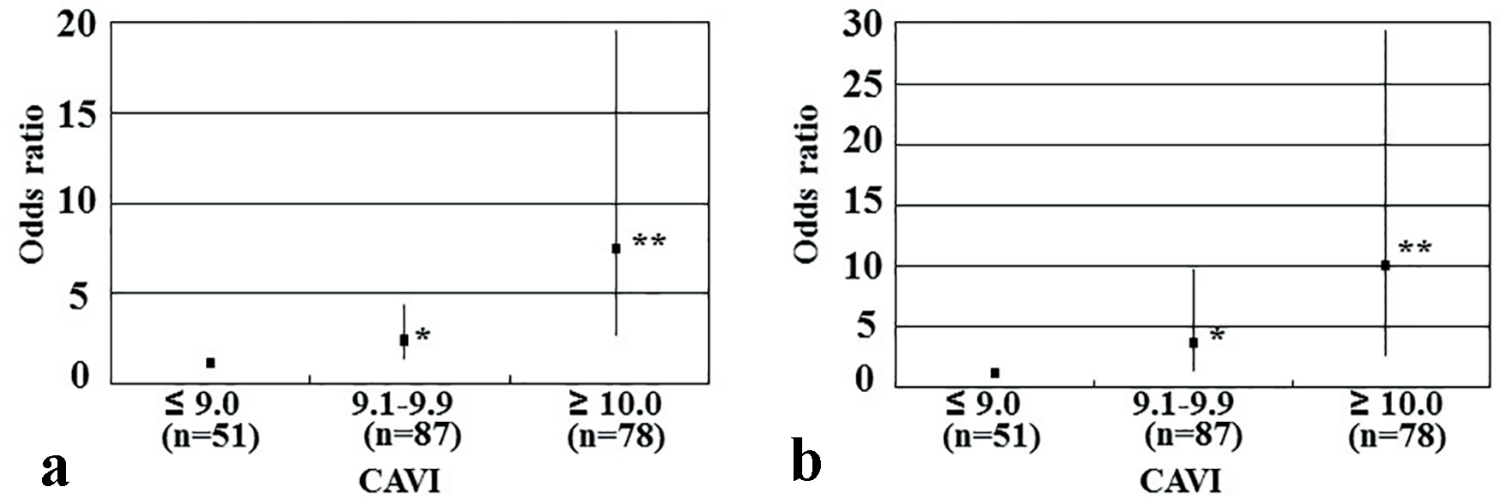

Figure 2. Results of multiple logistic regression analysis of CVD incidence or high hs-cTnT levels. (a) Subordinate factor is CVD incidence. Adjustment factors are skin autofluorescence, hs-cTnT, d-ROMs test, and age. (b) Subordinate factor is high hs-cTnT levels. High hs-cTnT was defined as hs-cTnT $\geq 0.014 \mathrm{ng} / \mathrm{mL}$. Adjustment factors are skin autofluorescence, CVD, d-ROMs test, and age. ${ }^{*} \mathrm{P}<0.05$ vs. $\mathrm{CAVI} \leq 9$; ${ }^{*} \mathrm{P}<0.001$ vs. $\mathrm{CAVI} \leq 9$. CAVI: cardio-ankle vascular index; CVD: cardiovascular disease; hscTnT: high-sensitivity cardiac troponin T; d-ROMs: derivatives of reactive oxygen metabolites.

patients with type 2 diabetes mellitus [5]. Mean CAVI value in this study population was 9.8 , and the results of this and other studies indicate that age is an independent factor for high CAVI values in patients with type 2 diabetes mellitus [43]. However, CAVI can be decreased by medication, and increasing physical activity is an independent factor for improving CAVI values in patients with diabetes mellitus [44]. Therefore, we believe that the risk of CVD incidence in elderly patients with type 2 diabetes mellitus can be reduced through interventions, such as the use of appropriate medications or an improvement in physical activity, with target CAVI values of $>9-10$.

\section{Limitations}

This study has several limitations. First, medical treatments for diabetes mellitus, hypertension, and/or dyslipidemia may have affected the study results. Second, a substantial number of patients without CVD did not undergo modalities, such as angiography, computed tomography, magnetic resonance imaging, and echocardiography; therefore, asymptomatic CVD may have remained undetected. Third, the HOMA-IR has limitations as a marker of insulin resistance, particularly in patients with high blood glucose levels, and this study included patients with high fasting blood glucose levels. Therefore, additional studies using another accurate insulin resistance marker, such as a glucose clamp test, are warranted to evaluate the association between insulin resistance and CAVI. Finally, the study design was single-center cross-sectional study, and the sample size was relatively small. Additional prospective studies, including evaluations of interventional therapies, are required to clarify the clinical significance of CAVI as a risk factor for CVD in elderly patients with type 2 diabetes mellitus.

\section{Conclusions}

Findings of this study indicate that CAVI is a novel marker of arterial function, which may be an important CVD risk factor in elderly patients with type 2 diabetes mellitus. Further investigations in a large number of prospective studies, including intervention therapies, will be required to validate the results of this study.

\section{Competing Interests}

Author has no competing interests.

\section{Grant Support}

None.

\section{Financial Disclosure}

None.

\section{References}

1. Narayan KM, Boyle JP, Geiss LS, Saaddine JB, Thompson TJ. Impact of recent increase in incidence on future diabetes burden: U.S., 2005-2050. Diabetes Care. 2006;29(9):2114-2116.

2. Kirkman MS, Briscoe VJ, Clark N, Florez H, Haas LB, Halter JB, Huang ES, et al. Diabetes in older adults. Diabetes Care. 2012;35(12):2650-2664.

3. Charvat H, Goto A, Goto M, Inoue M, Heianza Y, Arase Y, Sone $\mathrm{H}$, et al. Impact of population aging on trends in diabetes prevalence: A meta-regression analysis of 160,000 Japanese adults. J Diabetes Investig. 2015;6(5):533-542.

4. Shirai K, Hiruta N, Song M, Kurosu T, Suzuki J, Tomaru T, Miyashita Y, et al. Cardio-ankle vascular index (CAVI) as a novel indicator of arterial stiffness: theory, evidence and 
perspectives. J Atheroscler Thromb. 2011;18(11):924938.

5. Chung SL, Yang CC, Chen CC, Hsu YC, Lei MH. Coronary artery calcium score compared with cardio-ankle vascular index in the prediction of cardiovascular events in asymptomatic patients with type 2 diabetes. J Atheroscler Thromb. 2015;22(12):1255-1265.

6. Kim KJ, Lee BW, Kim HM, Shin JY, Kang ES, Cha BS, Lee EJ, et al. Associations between cardio-ankle vascular index and microvascular complications in type 2 diabetes mellitus patients. J Atheroscler Thromb. 2011;18(4):328336.

7. Friedewald WT, Levy RI, Fredrickson DS. Estimation of the concentration of low-density lipoprotein cholesterol in plasma, without use of the preparative ultracentrifuge. Clin Chem. 1972;18(6):499-502.

8. Matthews DR, Hosker JP, Rudenski AS, Naylor BA, Treacher DF, Turner RC. Homeostasis model assessment: insulin resistance and beta-cell function from fasting plasma glucose and insulin concentrations in man. Diabetologia. 1985;28(7):412-419.

9. Meerwaldt R, Links TP, Graaff R, Hoogenberg $\mathrm{K}$, Lefrandt JD, Baynes JW, Gans RO, et al. Increased accumulation of skin advanced glycation end-products precedes and correlates with clinical manifestation of diabetic neuropathy. Diabetologia. 2005;48(8):1637-1644.

10. Imai E, Horio M, Nitta K, Yamagata K, Iseki K, Hara $\mathrm{S}$, Ura N, et al. Estimation of glomerular filtration rate by the MDRD study equation modified for Japanese patients with chronic kidney disease. Clin Exp Nephrol. 2007;11(1):41-50.

11. Mingels A, Jacobs L, Michielsen E, Swaanenburg J, Wodzig W, van Dieijen-Visser M. Reference population and marathon runner sera assessed by highly sensitive cardiac troponin $\mathrm{T}$ and commercial cardiac troponin $\mathrm{T}$ and I assays. Clin Chem. 2009;55(1):101-108.

12. Cesarone MR, Belcaro G, Carratelli M, Cornelli U, De Sanctis MT, Incandela L, Barsotti A, et al. A simple test to monitor oxidative stress. Int Angiol. 1999;18(2):127-130.

13. Kanamoto M, Matsumoto N, Shiga T, Kunimoto F, Saito S. Relationship between coronary artery stenosis and cardio-ankle vascular index (CAVI) in patients undergoing cardiovascular surgery. J Cardiovasc Dis Res. 2013;4(1):15-19.

14. Saji N, Kimura K, Yagita Y, Kawarai T, Shimizu H, Kita Y. Comparison of arteriosclerotic indicators in patients with ischemic stroke: ankle-brachial index, brachial-ankle pulse wave velocity and cardio-ankle vascular index. Hypertens Res. 2015;38(5):323-328.

15. Zhang C, Ohira M, Iizuka T, Mikamo H, Nakagami T, Suzuki M, Hirano K, et al. Cardio-ankle vascular index relates to left ventricular ejection fraction in patients with heart failure. A retrospective study. Int Heart J. 2013;54(4):216-221.

16. Yan SF, Ramasamy R, Schmidt AM. The RAGE axis: a fundamental mechanism signaling danger to the vulnerable vasculature. Circ Res. 2010;106(5):842-853.

17. Chang JS, Wendt T, Qu W, Kong L, Zou YS, Schmidt AM, Yan SF. Oxygen deprivation triggers upregulation of early growth response- 1 by the receptor for advanced glycation end products. Circ Res. 2008;102(8):905-913.

18. Suga T, Iso T, Shimizu T, Tanaka T, Yamagishi S, Takeuchi M, Imaizumi T, et al. Activation of receptor for advanced glycation end products induces osteogenic differentiation of vascular smooth muscle cells. J Atheroscler Thromb. 2011;18(8):670-683.

19. Couppe C, Dall CH, Svensson RB, Olsen RH, Karlsen A, Praet S, Prescott E, et al. Skin autofluorescence is associated with arterial stiffness and insulin level in endurance runners and healthy controls - Effects of aging and endurance exercise. Exp Gerontol. 2017;91:9-14.

20. van Eupen MG, Schram MT, van Sloten TT, Scheijen J, Sep SJ, van der Kallen CJ, Dagnelie PC, et al. Skin Autofluorescence and Pentosidine Are Associated With Aortic Stiffening: The Maastricht Study. Hypertension. 2016;68(4):956-963.

21. Yamagishi S, Nakamura K, Imaizumi T. Advanced glycation end products (AGEs) and diabetic vascular complications. Curr Diabetes Rev. 2005;1(1):93-106.

22. Genevieve M, Vivot A, Gonzalez C, Raffaitin C, Barberger-Gateau P, Gin H, Rigalleau V. Skin autofluorescence is associated with past glycaemic control and complications in type 1 diabetes mellitus. Diabetes Metab. 2013;39(4):349-354.

23. Giugliano D, Ceriello A, Paolisso G. Oxidative stress and diabetic vascular complications. Diabetes Care. 1996;19(3):257-267.

24. Lipinski B. Pathophysiology of oxidative stress in diabetes mellitus. J Diabetes Complications. 2001;15(4):203210 .

25. Miyashita Y, Saiki A, Endo K, Ban N, Yamaguchi T, Kawana H, Nagayama D, et al. Effects of olmesartan, an angiotensin II receptor blocker, and amlodipine, a calcium channel blocker, on Cardio-Ankle Vascular Index (CAVI) in type 2 diabetic patients with hypertension. J Atheroscler Thromb. 2009;16(5):621-626.

26. Miyashita Y, Endo K, Saiki A, Ban N, Yamaguchi T, Kawana H, Nagayama D, et al. Effects of pitavastatin, a 3-hydroxy-3-methylglutaryl coenzyme a reductase inhibitor, on cardio-ankle vascular index in type 2 diabetic patients. J Atheroscler Thromb. 2009;16(5):539-545.

27. Gomez-Marcos MA, Blazquez-Medela AM, Gamella-Pozuelo L, Recio-Rodriguez JI, Garcia-Ortiz L, Martinez-Salgado C. Serum superoxide dismutase is associated with vascular structure and function in hypertensive and diabetic patients. Oxid Med Cell Longev. 2016;2016:9124676.

28. Hitsumoto T. Clinical impact of hemorheology assessed using the microchannel array flow analyzer on renal resistive index in patients with type 2 diabetes mellitus. J Endocrinol Metab. 2017;7(5):146-152.

29. Hitsumoto T. Impact of hemorheology assessed by the microchannel method on pulsatility index of the common carotid artery in patients with type 2 diabetes mellitus. J Clin Med Res. 2017;9(7):579-585.

30. Alam MA, Chowdhury MRH, Jain P, Sagor MAT, Reza HM. DPP-4 inhibitor sitagliptin prevents inflammation and oxidative stress of heart and kidney in two kidney and 
one clip (2K1C) rats. Diabetol Metab Syndr. 2015;7:107.

31. Lodovici M, Bigagli E, Tarantini F, Di Serio C, Raimondi L. Losartan reduces oxidative damage to renal DNA and conserves plasma antioxidant capacity in diabetic rats. Exp Biol Med (Maywood). 2015;240(11):1500-1504.

32. Hitsumoto T, Iizuka T, Takahashi M, Nakamura K, Shimizu K, Satoh S, Sugiyama Y, et al. [A relationship between insulin resistance and reduction in oxidative stress in vivo by atorvastatin]. J Cardiol. 2004;44(6):233-242.

33. Tahara N, Yamagishi SI, Bekki M, Kodama N, Nakamura T, Sugiyama Y, Oshige T, et al. Anagliptin, A dipeptidyl peptidase-4 inhibitor ameliorates arterial stiffness in association with reduction of remnant-like particle cholesterol and alanine transaminase levels in type 2 diabetic patients. Curr Vasc Pharmacol. 2016;14(6):552-562.

34. Resl M, Clodi M, Vila G, Luger A, Neuhold S, Wurm R, Adlbrecht C, et al. Targeted multiple biomarker approach in predicting cardiovascular events in patients with diabetes. Heart. 2016;102(24):1963-1968.

35. Bai Y, Ye P, Luo L, Xiao W, Xu R, Wu H, Bai J. Arterial stiffness is associated with minimally elevated high-sensitivity cardiac, troponin T levels in a community-dwelling population. Atherosclerosis. 2011;218(2):493-498.

36. Hitsumoto T. Factors Associated with High-sensitivity Cardiac Troponin T in Patients with Type 2 Diabetes Mellitus. J Nippon Med Sch. 2015;82(6):274-280.

37. Jaroch J, Loboz Grudzien K, Bociaga Z, Kowalska A, Kruszynska E, Wilczynska M, Dudek K. The relationship of carotid arterial stiffness to left ventricular diastolic dysfunction in untreated hypertension. Kardiol Pol.
2012;70(3):223-231

38. Sakane K, Miyoshi T, Doi M, Hirohata S, Kaji Y, Kamikawa S, Ogawa $\mathrm{H}$, et al. Association of new arterial stiffness parameter, the cardio-ankle vascular index, with left ventricular diastolic function. J Atheroscler Thromb. 2008;15(5):261-268.

39. Endo K, Saiki A, Ohira M, Miyashita Y, Shirai K. Cardioankle vascular index may reflect endothelial function in type 2 diabetes. Int J Clin Pract. 2011;65(11):1200-1201.

40. Leung M, Phan V, Leung DY. Endothelial function and left ventricular diastolic functional reserve in type 2 diabetes mellitus. Open Heart. 2014;1(1):e000113.

41. Marti V, Aymat R, Ballester M, Garcia J, Carrio I, Auge JM. Coronary endothelial dysfunction and myocardial cell damage in chronic stable idiopathic dilated cardiomyopathy. Int J Cardiol. 2002;82(3):237-245.

42. Saunders JT, Nambi V, de Lemos JA, Chambless LE, Virani SS, Boerwinkle E, Hoogeveen RC, et al. Cardiac troponin $\mathrm{T}$ measured by a highly sensitive assay predicts coronary heart disease, heart failure, and mortality in the Atherosclerosis Risk in Communities Study. Circulation. 2011;123(13):1367-1376.

43. Tian G, Wei W, Zhang W, Zhang L, You H, Liu W, Sun Z, et al. Increasing age associated with elevated cardio-ankle vascular index scores in patients with type 2 diabetes mellitus. J Int Med Res. 2013;41(2):435-444.

44. Iwasa $\mathrm{T}$, Amiya $\mathrm{E}$, Ando J, Watanabe M, Murasawa $\mathrm{T}$, Komuro I. Different contributions of physical activity on arterial stiffness between diabetics and non-diabetics. PLoS One. 2016;11(8):e0160632. 